\title{
Application of Discrete S-Transform for Differential Protection of Power Transformers
}

\author{
A. Ashrafian, M. Rostami, G. B. Gharehpetian, and M. Gholamghasemi
}

\begin{abstract}
In this paper, a novel scheme based on Hyperbolic S-Transform (HST) is proposed for digital differential protection of power transformers. Hyperbolic S-transform is a powerful tool for non-stationary signal analysis in noisy conditions. Decision logic has been devised using extracted feature from differential currents due to transient phenomena in transformers. The HST of the differential current is calculated. Then, a Decision Index $(D I)$ is calculated according to the spectral energy and standard deviation of the $S$-matrix. It is seen that DI values are different in the cases of internal faults and inrush currents. The scheme has been implemented in MATLAB environment and the inputs are differential currents derived from EMTP software. In order to simulate the internal turn to turn and turn to earth faults, the power transformer is modeled using $8 \times 8 \mathrm{RL}$ matrices obtained from the subroutine BCTRAN of EMTP software. The differential current signals are infected by noise and the robustness of the algorithm under noisy conditions is investigated.
\end{abstract}

Index Terms-Fault, inrush current, protection, s-transform, transformer.

\section{INTRODUCTION}

The differential protection concepts are based on the assumption that while an internal fault, the differential current becomes higher than the normal conditions. But, the inrush currents can induce a high differential current due to core saturation and cause mal-operation of differential relays. So, different techniques have been suggested for overcoming this problem. The magnetizing inrush current has a large second order harmonic component in comparison to internal faults. In [1]-[2] the second harmonic component of the differential currents is used to restrain operation of the differential relay to avoid tripping during magnetizing inrush currents. However, a large second harmonic component may be generated during internal faults due to $\mathrm{CT}$ saturation or presence of a shunt capacitor in long transmission line to which the power transformer is connected. Furthermore, the magnitude of second order harmonic in inrush currents has been reduced because of the improvement of core materials. In [3] a wavelet packet-based algorithm has been suggested.

Manuscript received February 15, 2012; revised March 15, 2012.

A. Ashrafian is with the Department of Engineering, Shahed University Tehran, Iran and Department of Engineering, Shahre-rey branch, Islamic Azad University, Tehran, Iran. (e-mail: a.ashrafian @ieee.org).

M. Rostami is with the Department of Engineering, Shahed University, Tehran, Iran (e-mail: rostami@shahed.ac.ir).

G. B. Gharehpetian is with the Electrical Engineering Department, Amirkabir University of Technology, Tehran, Iran (e-mail: grptian@aut.ac.ir).

M. Gholamghasemi is with the Department of Electrical Engineering Noshirvani University, Babol, Iran (e-mail: ghasemi_maede69@yahoo.com ).
This method requires the measurement of the voltage in addition to current. Therefore, it needs a large amount of computation. Recently, some protective schemes have been suggested using a combination of Discrete Wavelet Transform (DWT) and Fuzzy logic [4], Artificial Neural Networks [5], and correlation factor [6]. But, these methods are system dependent and have high dependency to the parameters of the protected system. In addition, discrete wavelet transform based schemes are easily affected by noise [7]. So, S-transform based methods have been suggested for overcoming the noise problems in [7]-[10]. However, the turn to turn and the turn to earth faults are not investigated in these works.

This paper presents an S-transform based method for discrimination between inrush current and internal short circuits. The internal faults while transformer energization, turn to turn and turn to earth faults are considered, too. The HST is employed and the three-phase differential currents are analyzed. The spectral energy and the standard deviation of the S-matrix are computed. Then, a decision index is calculated, using the spectral energy and the standard deviation of the S-matrix. The proposed scheme employs the decision index, and discriminates internal faults from the inrush current. The turn to earth and turn to turn faults and transformer energizing while internal fault, are investigated.

\section{THE HYPERBOLIC S-TRANSFORM}

The S-transform of $h(t)$ given by Stockwell is [11]:

$$
S(\tau, f)=\int_{-\infty}^{+\infty} h(t)\left[\begin{array}{l}
|f| / \sqrt{2 \pi} \\
\times \exp \left(-f^{2}(\tau-t)^{2} / 2\right. \\
\times \exp (-2 \pi i f t)
\end{array}\right] d t
$$

where $\mathrm{S}$ denotes the $\mathrm{S}$-transform of $h(t)$, which is time varying signals. $f$ denotes the frequency and $\tau$ is a parameter which controls the position of Gaussian window on the $t$-axis. The generalized S-transform can be obtained from original S-transform by replacing the Gaussian window with a generalized window [9]:

$$
S(\tau, f, p)=\int_{-\infty}^{+\infty} h(t) w(\tau-t, f, p) \exp (-2 \pi i f t) d t
$$

where $p$ denotes a set of parameter that control the shape of generalized window. The hyperbolic S-transform is obtained from the generalized S-transform, by replacing the 
generalized window with a hyperbolic window [9]:

$$
\begin{aligned}
& w_{\text {hyp }}=\frac{2|f|}{\sqrt{2 \pi}\left(\gamma_{f}+\gamma_{b}\right)} \\
& \times \exp \left[\frac{-f^{2}\left[X\left(\tau-t,\left\{\gamma_{f}, \gamma_{b}, \lambda_{\text {hyp }}{ }^{2}\right\}\right)\right]^{2}}{2}\right]
\end{aligned}
$$

where

$$
\begin{aligned}
& X\left(\tau-t,\left\{\gamma_{f}, \gamma_{b}, \lambda_{\text {hyp }}{ }^{2}\right\}\right)=\left[\frac{\gamma_{f}+\gamma_{b}}{2 \gamma_{f} \gamma_{b}}\right](\tau-t-\zeta) \\
& +\left[\frac{\gamma_{f}-\gamma_{b}}{2 \gamma_{f} \gamma_{b}}\right] \sqrt{(\tau-t-\zeta)^{2}+\lambda_{\text {hyp }}^{2}}
\end{aligned}
$$

$X$ is hyperbola in $(\tau-t)$ and its shape is defined by $\gamma_{f}, \gamma_{b}$ and $\lambda_{\text {hyp }}$. Where $\gamma_{f}$ and $\gamma_{b}$ are forward-taper and backward-taper parameters, respectively. $\lambda_{\text {hyp }}$ is the positive curvature parameter and $\zeta$ is defined as:

$$
\zeta=\sqrt{\frac{\left(\gamma_{f}-\gamma_{b}\right)^{2} \lambda_{h y p}^{2}}{4 \gamma_{f} \gamma_{b}}}
$$

Since, a symmetrical window provides better frequency resolution than an asymmetrical window. So, at high frequencies, where the window is narrow and time resolution is good, the shape of the window converges toward the Gaussian window, a symmetrical window. But, at low frequencies a very asymmetrical window is used. The discrete version of the hyperbolic S-transform of $h[k T]$ is given by:

$$
S[n, j]=\sum_{m=0}^{N-1} H(m+n) G(m, n) \exp (i 2 \pi m j)
$$

where $N$ is the total number of samples and $n, m$ and $j$ varies 0 to $N-1 . G(m, n)$ is the Fourier transform of the hyperbolic window and $H(m, n)$ is the frequency shifted discrete Fourier transform $H[m]$.

\section{Simulation MODELS}

The simulation model is developed using EMTP program. The power system under study is shown in Fig.1. The simulated transformer is a three phase power transformer with the rating of $31.5 \mathrm{MVA}, 132 / 33 \mathrm{kV}$ [12]. The primary winding has 980 turns wound in 10 layers and the secondary winding has 424 turns wound in 4 layers. The transmission line has been modeled by two identical $\pi$ sections. The algorithm has been implemented on MATLAB environment and the inputs are differential currents derived from EMTP software.

If a transformer terminal model is known in terms of winding resistance, self and mutual inductances, therefore, $6 \times 6 \mathrm{RL}$ matrices from BCTRAN routine can be formed for a three phase two winding transformer, and also $7 \times 7$ and $8 \times 8$ matrices can be derived for turn to earth and turn to turn fault studies, respectively [13]-[14]. So, in order to simulate turn to turn and turn to earth faults, the b-phase of primary winding is divided into three parts with 637, 49 and 294 turns, as shown in Fig.2. Hence, $8 \times 8$ RL matrices are determined for the modeled transformer. Small shunt capacitances are connected across the windings to consider the high frequency behavior of the transformer. In order to simulate the magnetic characteristic of the transformer core non-linear hysteretic reactors are connected on secondary side.

\section{Simulation Results}

Various operating conditions are simulated and the differential currents are obtained from secondary of the current transformers. Typical differential currents and time-frequency contours are illustrated in Figs.3-5. Differential current and it's time-frequency contours for an inrush current is presented in Fig.3. As it is clear, the contours are interrupted and there is a consistent time interval between two lobes. Fig.4 shows differential current and time-frequency contours for internal turn to turn fault between turns 294 and 343. Unlike inrush current, the contours are regular and they are not interrupted. A typical differential current for transformer energizing while turn to turn fault, is shown in Fig.5. As it is seen, the time-frequency contours are the same as the internal fault case.

In order to investigate noisy conditions, random noise with SNR up to $20 \mathrm{~dB}$ has been added to the differential current signals. The results are shown in Figs.6-8. These cases are the same as cases that shown in Figs3-5, but are contaminated with noise. It is found, the time-frequency contours are less influenced by noise.

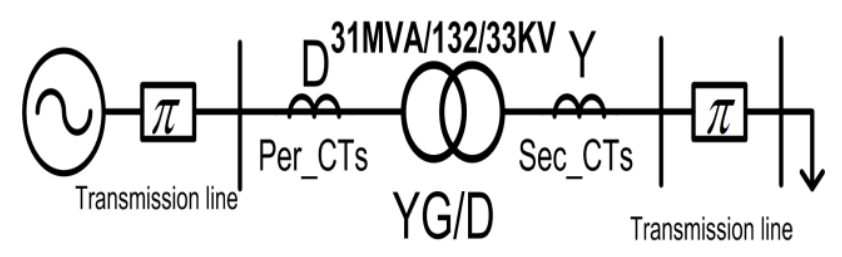

Fig.1 Simulated power system

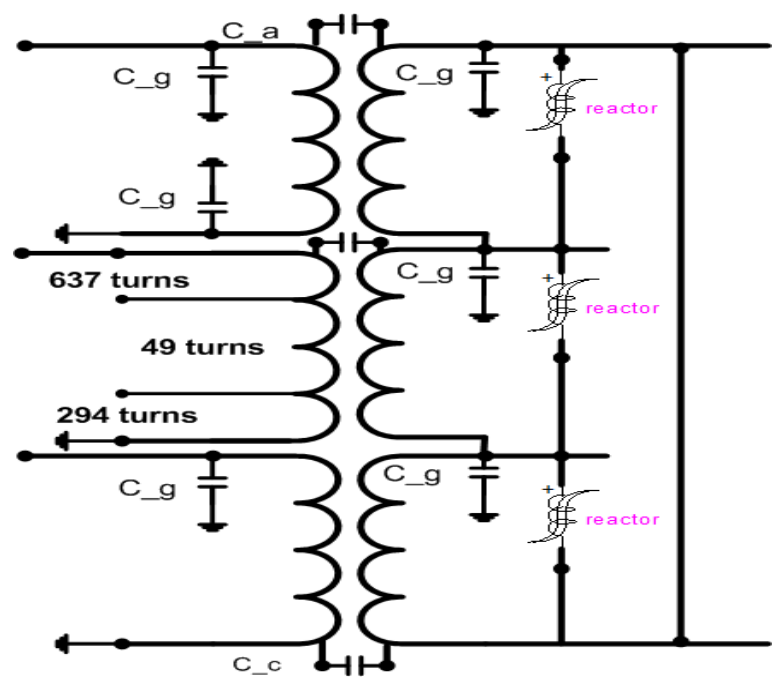

Fig. 2 transformer model 

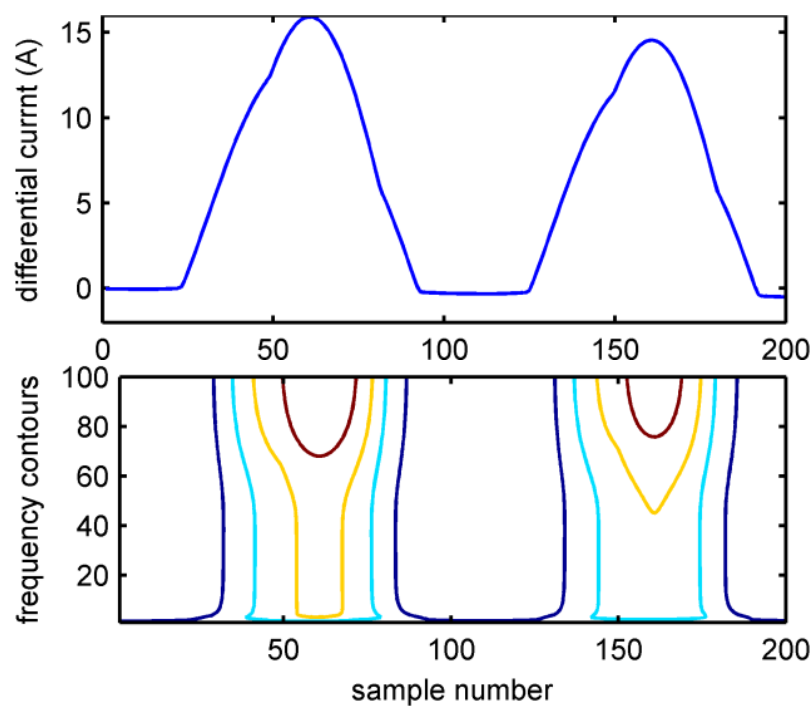

Fig. 3. Differential current and S-contours for a magnetizing inrush current with no load
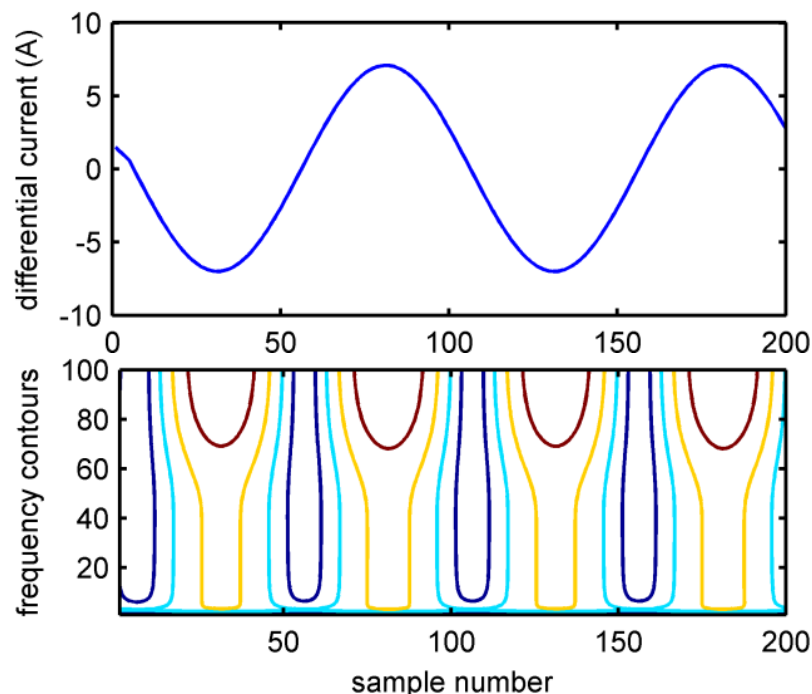

Fig. 4. b-phase differential current and S-contours for internal fault between turns 294 and 343 of primary winding
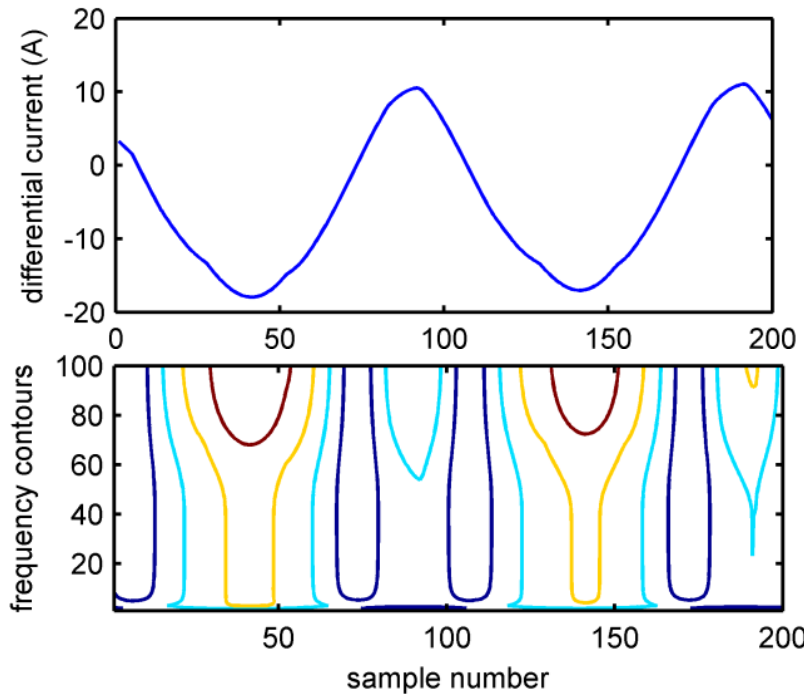

Fig. 5. b-phase differential current and S-contours for inrush current while turn to turn fault between turns 294 and 343.
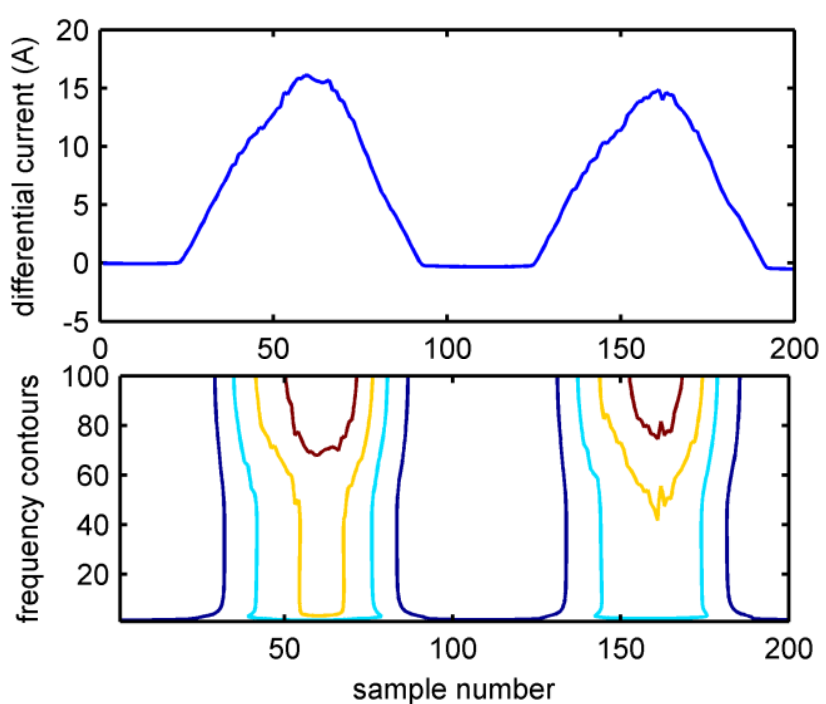

Fig. 6. Differential current with SNR 20dB and S-contours for a magnetizing inrush current with no load
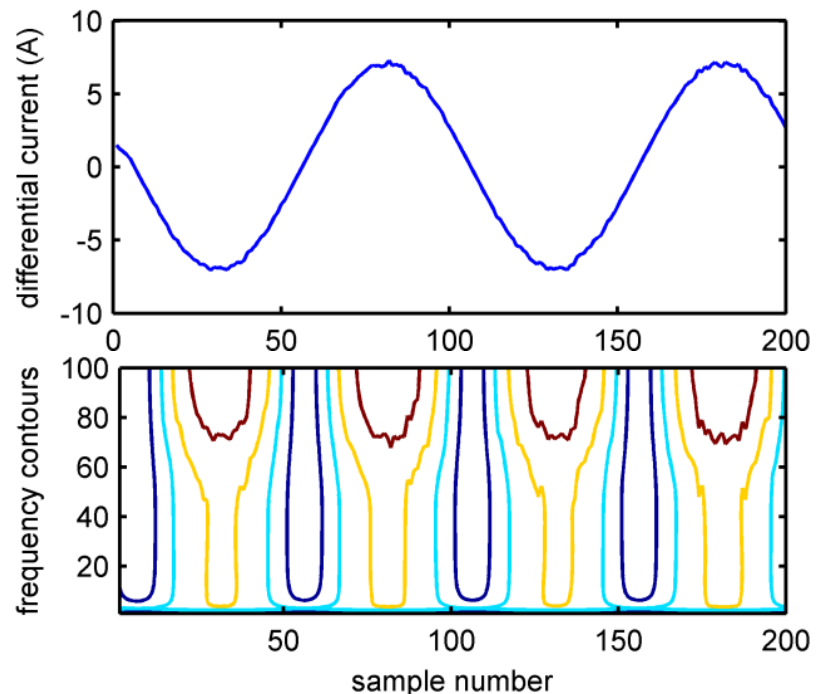

Fig.7. b-phase differential current with SNR $20 \mathrm{~dB}$ and S-contours for internal fault between turns 294 and 343 of primary winding.
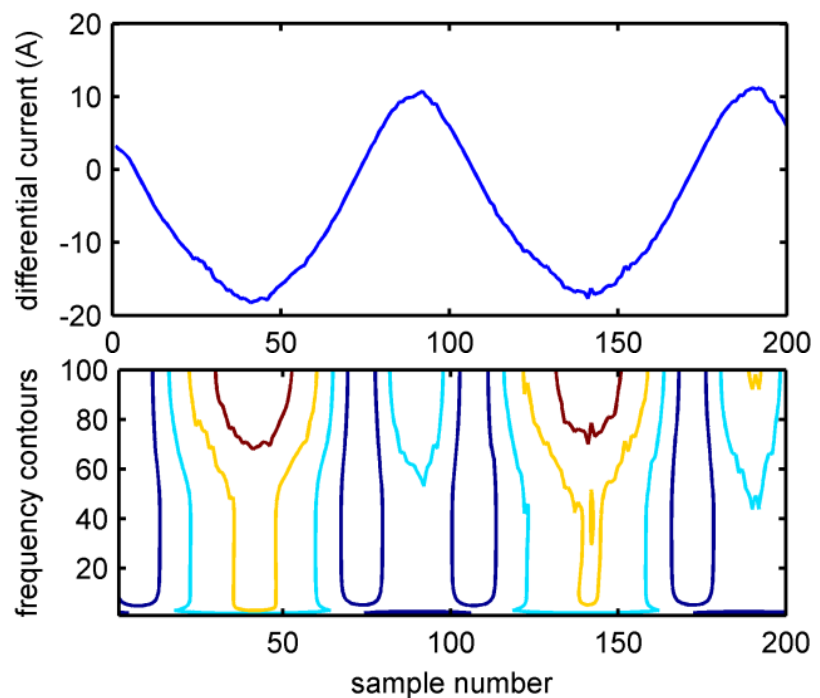

Fig. 8. b-phase differential current with SNR $20 \mathrm{~dB}$ and S-contours for inrush current while turn to turn fault between turns 294 and 343. 
TABLE I: SIMULATION RESULTS

\begin{tabular}{|c|c|c|c|c|c|c|c|c|c|}
\hline \multirow{2}{*}{$\begin{array}{l}\text { inr/fault } \\
\text { type }\end{array}$} & \multirow{2}{*}{ 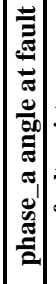 } & \multirow{2}{*}{ 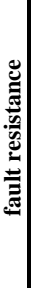 } & \multirow[t]{2}{*}{$\begin{array}{l}\ddot{\mathscr{D}} \\
:\end{array}$} & \multicolumn{3}{|c|}{ Without noise } & \multicolumn{3}{|c|}{ Infected with noise } \\
\hline & & & & Energy & STD & DI & Energy & STD & DI \\
\hline \multirow{3}{*}{$\begin{array}{c}\text { inr } \\
\text { noload }\end{array}$} & \multirow{3}{*}{0} & \multirow{3}{*}{ no } & A & $8.55 \mathrm{E}+03$ & $1.46 \mathrm{E}+02$ & $1.25 \mathrm{E}+06$ & 8.47E+03 & $1.46 \mathrm{E}+02$ & $1.24 \mathrm{E}+06$ \\
\hline & & & B & $7.56 \mathrm{E}+03$ & $1.44 \mathrm{E}+02$ & $1.09 \mathrm{E}+06$ & $7.55 \mathrm{E}+03$ & $1.44 \mathrm{E}+02$ & $1.09 E+06$ \\
\hline & & & C & $1.56 \mathrm{E}+04$ & $2.29 E+02$ & $3.59 \mathrm{E}+06$ & $1.57 \mathrm{E}+04$ & $2.30 \mathrm{E}+02$ & $3.61 E+06$ \\
\hline \multirow{3}{*}{$\begin{array}{c}\text { inr } \\
\text { nolod }\end{array}$} & \multirow{3}{*}{60} & \multirow{3}{*}{ no } & A & $7.57 \mathrm{E}+03$ & $1.44 \mathrm{E}+02$ & $1.09 \mathrm{E}+06$ & $7.52 \mathrm{E}+03$ & $1.44 \mathrm{E}+02$ & $1.08 \mathrm{E}+06$ \\
\hline & & & B & $1.56 \mathrm{E}+04$ & $2.29 E+02$ & $3.59 E+06$ & $1.56 \mathrm{E}+04$ & $2.29 E+02$ & $3.57 \mathrm{E}+06$ \\
\hline & & & C & $8.66 \mathrm{E}+03$ & $1.46 \mathrm{E}+02$ & $1.27 \mathrm{E}+06$ & $8.70 \mathrm{E}+03$ & $1.46 \mathrm{E}+02$ & $1.27 \mathrm{E}+06$ \\
\hline \multirow{3}{*}{$\begin{array}{c}\text { inr } \\
\text { noload }\end{array}$} & \multirow{3}{*}{90} & \multirow{3}{*}{ no } & A & $1.27 \mathrm{E}+04$ & $2.05 E+02$ & $2.61 \mathrm{E}+06$ & $1.28 \mathrm{E}+04$ & $2.06 \mathrm{E}+02$ & $2.63 E+06$ \\
\hline & & & B & $1.36 \mathrm{E}+04$ & $2.06 E+02$ & $2.80 \mathrm{E}+06$ & $1.36 \mathrm{E}+04$ & $2.06 \mathrm{E}+02$ & $2.81 \mathrm{E}+06$ \\
\hline & & & C & $5.93 \mathrm{E}+03$ & $1.35 \mathrm{E}+02$ & $7.98 \mathrm{E}+05$ & $5.94 E+03$ & $1.35 \mathrm{E}+02$ & $8.00 \mathrm{E}+05$ \\
\hline \multirow{3}{*}{ inr noload } & \multirow{3}{*}{150} & \multirow{3}{*}{ no } & A & $1.37 \mathrm{E}+04$ & $2.06 E+02$ & $2.82 \mathrm{E}+06$ & $1.37 \mathrm{E}+04$ & $2.06 \mathrm{E}+02$ & $2.82 \mathrm{E}+06$ \\
\hline & & & B & $5.93 \mathrm{E}+03$ & $1.35 \mathrm{E}+02$ & $7.97 \mathrm{E}+05$ & $5.96 \mathrm{E}+03$ & $1.35 \mathrm{E}+02$ & $8.03 E+05$ \\
\hline & & & C & $1.27 \mathrm{E}+04$ & $2.05 E+02$ & $2.61 E+06$ & $1.27 \mathrm{E}+04$ & $2.05 E+02$ & $2.61 \mathrm{E}+06$ \\
\hline \multirow{3}{*}{ inr with load } & \multirow{3}{*}{0} & \multirow{3}{*}{ no } & A & $8.18 \mathrm{E}+03$ & $1.46 \mathrm{E}+02$ & $1.19 \mathrm{E}+06$ & $8.14 \mathrm{E}+03$ & $1.46 \mathrm{E}+02$ & $1.19 \mathrm{E}+06$ \\
\hline & & & B & $6.09 \mathrm{E}+03$ & $1.30 \mathrm{E}+02$ & $7.95 E+05$ & $6.05 E+03$ & $1.30 \mathrm{E}+02$ & $7.88 \mathrm{E}+05$ \\
\hline & & & $\mathrm{C}$ & $1.42 \mathrm{E}+04$ & $2.19 E+02$ & $3.11 E+06$ & 1.42E+04 & $2.20 \mathrm{E}+02$ & $3.11 E+06$ \\
\hline inr & & & A & $6.10 \mathrm{E}+03$ & $1.31 \mathrm{E}+02$ & $7.97 \mathrm{E}+05$ & $6.13 E+03$ & $1.31 \mathrm{E}+02$ & $8.02 \mathrm{E}+05$ \\
\hline with load & 60 & no & B & $1.42 \mathrm{E}+04$ & $2.19 E+02$ & $3.11 E+06$ & $1.42 \mathrm{E}+04$ & $2.19 \mathrm{E}+02$ & $3.11 E+06$ \\
\hline & & & C & $8.29 \mathrm{E}+03$ & $1.46 \mathrm{E}+02$ & $1.21 \mathrm{E}+06$ & $8.25 \mathrm{E}+03$ & $1.46 \mathrm{E}+02$ & $1.20 \mathrm{E}+06$ \\
\hline inr +int & & & A & $6.40 \mathrm{E}+03$ & $1.28 \mathrm{E}+02$ & $8.21 E+05$ & $6.37 \mathrm{E}+03$ & $1.28 \mathrm{E}+02$ & $8.16 E+05$ \\
\hline 294 to & 0 & 0 & B & $3.94 \mathrm{E}+07$ & $1.27 \mathrm{E}+03$ & $5.00 \mathrm{E}+10$ & 3.90E+07 & $1.27 \mathrm{E}+03$ & $4.95 \mathrm{E}+10$ \\
\hline earth & & & $\mathrm{C}$ & $3.95 \mathrm{E}+07$ & $1.30 \mathrm{E}+03$ & $5.12 \mathrm{E}+10$ & $4.00 \mathrm{E}+07$ & $1.30 \mathrm{E}+03$ & $5.20 \mathrm{E}+10$ \\
\hline & & & A & $4.99 \mathrm{E}+03$ & $1.23 \mathrm{E}+02$ & $6.11 \mathrm{E}+05$ & $5.01 E+03$ & $1.23 \mathrm{E}+02$ & $6.15 E+05$ \\
\hline+ int turns & 30 & 6 & B & $2.76 \mathrm{E}+05$ & $2.72 \mathrm{E}+02$ & $7.50 \mathrm{E}+07$ & $2.82 \mathrm{E}+05$ & $2.72 E+02$ & $7.67 \mathrm{E}+07$ \\
\hline 294 to earth & & & C & $3.07 \mathrm{E}+05$ & $3.47 \mathrm{E}+02$ & $1.07 \mathrm{E}+08$ & $3.11 \mathrm{E}+05$ & $3.49 E+02$ & $1.08 \mathrm{E}+08$ \\
\hline & & & $\mathrm{A}$ & $1.30 \mathrm{E}+04$ & $2.00 \mathrm{E}+02$ & $2.59 \mathrm{E}+06$ & $1.31 \mathrm{E}+04$ & $2.00 \mathrm{E}+02$ & $2.61 E+06$ \\
\hline+ int turns & 0 & 0.1 & B & $2.37 \mathrm{E}+06$ & $2.52 \mathrm{E}+02$ & $5.98 \mathrm{E}+08$ & $2.44 \mathrm{E}+06$ & $2.52 \mathrm{E}+02$ & $6.15 E+08$ \\
\hline 294 to343 & & & C & $2.43 E+06$ & $3.82 \mathrm{E}+02$ & $9.28 \mathrm{E}+08$ & $2.43 \mathrm{E}+06$ & $3.82 \mathrm{E}+02$ & $9.30 \mathrm{E}+08$ \\
\hline int & & & A & $4.98 \mathrm{E}+00$ & $6.82 \mathrm{E}-01$ & $3.40 \mathrm{E}+00$ & $4.99 \mathrm{E}+00$ & $6.80 \mathrm{E}-01$ & $3.40 \mathrm{E}+00$ \\
\hline 294to & 0 & 0.1 & B & $3.24 \mathrm{E}+06$ & $4.33 \mathrm{E}+02$ & $1.40 \mathrm{E}+09$ & 3.14E+06 & $4.33 E+02$ & $1.36 \mathrm{E}+09$ \\
\hline 343 & & & C & 3. $25 \mathrm{E}+06$ & $4.34 \mathrm{E}+02$ & $1.41 \mathrm{E}+09$ & 3.18E+06 & $4.34 \mathrm{E}+02$ & $1.38 \mathrm{E}+09$ \\
\hline int & & & A & $4.98 \mathrm{E}+00$ & $6.82 \mathrm{E}-01$ & $3.40 \mathrm{E}+00$ & 5.04E+00 & $6.82 \mathrm{E}-01$ & $3.44 \mathrm{E}+00$ \\
\hline 294to & 90 & 0.1 & B & 3.24E+06 & $4.33 \mathrm{E}+02$ & $1.40 \mathrm{E}+09$ & 3. $25 E+06$ & $4.34 \mathrm{E}+02$ & $1.41 \mathrm{E}+09$ \\
\hline 343 & & & C & $3.25 \mathrm{E}+06$ & $4.34 \mathrm{E}+02$ & $1.41 \mathrm{E}+09$ & 3.22E+06 & $4.34 \mathrm{E}+02$ & $1.40 \mathrm{E}+09$ \\
\hline int & 90 & 3 & A & $8.46 \mathrm{E}+00$ & $6.79 \mathrm{E}-01$ & $5.74 \mathrm{E}+00$ & $8.47 \mathrm{E}+00$ & $6.79 \mathrm{E}-01$ & $5.75 \mathrm{E}+00$ \\
\hline turn & & & B & $2.37 \mathrm{E}+06$ & $5.12 \mathrm{E}+02$ & $1.21 \mathrm{E}+09$ & $2.44 E+06$ & $5.12 \mathrm{E}+02$ & $1.25 \mathrm{E}+09$ \\
\hline 294 to earth & & & $\mathrm{C}$ & $2.38 \mathrm{E}+06$ & $5.12 \mathrm{E}+02$ & $1.22 \mathrm{E}+09$ & $2.42 \mathrm{E}+06$ & $5.12 \mathrm{E}+02$ & $1.24 \mathrm{E}+09$ \\
\hline int & 30 & 5 & A & $6.89 \mathrm{E}-01$ & $6.79 \mathrm{E}-01$ & $4.68 \mathrm{E}-01$ & $6.82 \mathrm{E}-01$ & $6.79 \mathrm{E}-01$ & 4.63E-01 \\
\hline turn343 & & & B & $1.02 \mathrm{E}+06$ & $4.40 \mathrm{E}+02$ & $4.51 \mathrm{E}+08$ & $1.02 \mathrm{E}+06$ & $4.39 \mathrm{E}+02$ & $4.47 E+08$ \\
\hline to earth & & & C & $1.03 \mathrm{E}+06$ & $4.41 \mathrm{E}+02$ & $4.52 \mathrm{E}+08$ & $1.04 \mathrm{E}+06$ & $4.41 \mathrm{E}+02$ & $4.60 \mathrm{E}+08$ \\
\hline int & & & A & $4.58 \mathrm{E}+00$ & $6.77 \mathrm{E}-01$ & $3.10 \mathrm{E}+00$ & $4.60 \mathrm{E}+00$ & $6.77 \mathrm{E}-01$ & 3.12E+00 \\
\hline 343to & 0 & 3 & B & $8.80 \mathrm{E}+06$ & $6.45 \mathrm{E}+02$ & $5.67 \mathrm{E}+09$ & $8.57 \mathrm{E}+06$ & $6.44 \mathrm{E}+02$ & $5.52 \mathrm{E}+09$ \\
\hline earth & & & C & $8.81 \mathrm{E}+06$ & $6.45 E+02$ & $5.68 \mathrm{E}+09$ & 8. $60 \mathrm{E}+06$ & $6.45 \mathrm{E}+02$ & $5.55 E+09$ \\
\hline terminal & & & A & $4.73 \mathrm{E}+06$ & $4.87 \mathrm{E}+02$ & $2.31 \mathrm{E}+09$ & $4.74 \mathrm{E}+06$ & $4.87 \mathrm{E}+02$ & $2.31 \mathrm{E}+09$ \\
\hline ac & 0 & 0 & B & $2.53 \mathrm{E}+00$ & $6.87 \mathrm{E}-01$ & $1.74 \mathrm{E}+00$ & $2.50 \mathrm{E}+00$ & $6.87 \mathrm{E}-01$ & $1.72 \mathrm{E}+00$ \\
\hline & & & C & $4.74 \mathrm{E}+06$ & $4.87 \mathrm{E}+02$ & $2.31 \mathrm{E}+09$ & $4.85 E+06$ & $4.87 \mathrm{E}+02$ & $2.36 \mathrm{E}+09$ \\
\hline
\end{tabular}

Several internal faults with different fault resistances and fault incipient angles as well as several energizations with different switching angles have been simulated. In order to study the robustness of the scheme under noisy conditions, random noise with SNR up to $20 \mathrm{~dB}$ has been added to the differential current signals. The spectral energy and the standard deviation of the S-matrix of the differential currents are calculated. Then, a decision index is calculated by multiplying the spectral energy by standard deviation:

$$
D I=S T D \times E
$$

where $S T D$ and $E$ denote the standard deviation and the energy of the S-matrix, respectively. Simulation results for some cases are listed in Table.I. The results for noisy conditions are given, too. It is seen, the $D I$ values are lower than 3.59E+06, in the inrush cases but they are higher than $7.50 \mathrm{E}+07$, in the faulty phases and the $D I$ values are less influenced by noise. So, it is easy to discriminate between faulty and inrush conditions even in noisy environment and the energizing while internal fault. Notice that the turn to turn and the turn to earth faults are simulated in b-phase. Since the secondary windings of the transformer are connected as delta, a fault in the b-phase, results in high values of $D I$ in phases b and $\mathrm{c}$.

\section{CONCLUSION}

A new technique for discrimination between the internal fault and the inrush current in power transformer is suggested. A decision index is defined using the standard deviation and the spectral energy of the S-matrix, computed for an internal fault or an inrush current. Then, fault cases can be distinguished by comparison of the decision index with a threshold value. The proposed scheme was implemented using MATLAB and EMTP programs. Several cases have been studied to test the effectiveness of the approach. Simulation results validate the efficiency of the proposed algorithm even in the noisy conditions.

\section{REFERENCES}

[1] B. Kasztenny and A. Kulidjian, "An improved transformer inrush restraint algorithm increases security while maintaining fault response performance," 53rd Annual Conference for Protective Relay Engineers, Canada, Apr 11-13, 2000.

[2] H. Zhang, P. Liu, and O. P. Malik, "A new scheme for inrush identification in transformer protection," Electric Power System Research, vol. 63, no. 2, pp.81-86, 28 Sep, 2002.

[3] M. M. Eissa, "A novel digital directional transformer protection technique based on wavelet packet," IEEE Trans. Power Del., vol. 20, no. 3, pp. 1830-1836, Jul. 2005.

[4] N. Hoang Viet, "New approach for classifying transient phenomena in power transformer using discrete wavelet transforms(DWT) and fuzzy logic," International Symposium on Electrical \& Electronics Engineering , Oct 24-25, 2007.

[5] M. Geethanjali, S. M. Raja Slochanal, and R. Bhavani, "A novel approach for power transformer protection based upon combined wavelet transform and neural networks (WNN)," The $7^{\text {th }}$ International Power Engineering Conference,Nov.29-Dec2,2005, pp.1-6.

[6] H. Kazemi Kargar, M. Jabbari, and S. Golmohammad zadeh, "Inrush current identification based on wavelet transform and correlation factors," $6^{\text {th }}$ International Conference on Telecommunication and Technology, 2009.

[7] Q, Zhang, S, Jiao, and S, Wang, "Identification inrush current and internal faults of transformer based on Hyperbolic S-transform," $4^{\text {th }}$ 
IEEE Conference on Industrial Electronics and Applications, 2009, pp.258-263.

[8] S. Jia, S. Wang, and G. Zheng, "A new approach to identify inrush current based on generalized S-transform," International Conference on Electrical Machines and Systems, 2008, pp. 4317-4322.

[9] S. Sendilkumar, B. L. Mathur, and J. Henry, "A new technique to classify transient events in power transformer differential protection using S-transform," 3th International Conference on Power Systems, Kharagpur, INDIA Dec 27-29.2009, pp.1-6.

[10] B. K. Panigrahi, S. R. Samantaray, P. K. Dash, and G. Panda, "Discrimination between inrush current and internal faults using pattern recognition approach," International Conference on Power Electronics, Drives and Energy Systems, 2006.

[11] R. G. Stockwell, L. Mansinha, and R. P. Lowe, "Localization of the complex spectrum: the S transform," IEEE Trans. On signal processing, vol.44, no.4, pp.998-1001, Apr 1996.

[12] Simi P. Valsan and K. S. Swarup, "Wavelet based transformer protection using high frequency power directional signals," Electric Power Systems Research, vol.78, pp.547-558. 2008.

[13] P. Bastard, P. Bertrand, and M. Meunier, "A transformer model for winding fault studies," IEEE Trans.Power Del., vol. 9. no. 2, pp.690-699, Apr1994.

[14] M. Kezunovic and Y. Guo, "Modeling and simulation of the power transform faults and related protective relay behavior," IEEE Trans.Power Del., vol. 15, no.1, pp.44-50, Jan 2000.

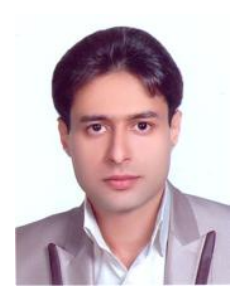

A. Ashrafian was born in Dezfoul, Iran in 1985. He received his B.S and M.S.C degrees in electrical power engineering from Islamic Azad University, South Tehran branch, Tehran, Iran, in 2008 and Department of Engineering, Shahed University, Tehran, Iran, in 2011, respectively. He serves as lecturer in Department of Engineering, Shahed University, Tehran, Iran and Department of Engineering, Shahre-rey branch, Islamic Azad University, Tehran, Iran.

He has been the author of several papers published in journals and presented at national and international conferences. His research interests include transient analysis of power system, digital signal processing, power system protection and relaying, transformer dielectric testing and power quality monitoring.

Mr. Ashrafian is a member of IEEE.

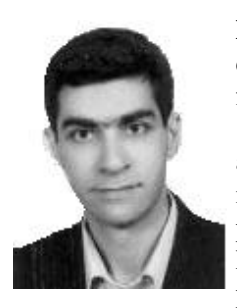

Mehrdad Rostami received his BS, MS and Ph.D degrees in electrical engineering in 1989, 1992 and 2003 from Amirkabir University of Technology (AUT).

$\mathrm{He}$ is the author of more than 60 papers in journals and conferences. Being IEEE member, he has been involved in reviewing several journal and conference papers in his field (Transient, Reliability, Chaos and Ferro resonance in power system). He has been assistant professor of Shahed University since 2004 and has been nominated to upgrade to associate Professor recently.

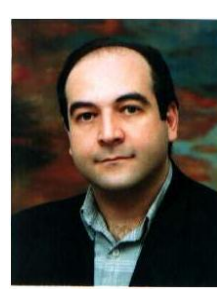

G. B. Gharehpetian received his BS, MS and Ph.D degrees in electrical engineering in 1987, 1989 and 1996 from Tabriz University, Tabriz, Iran and Amirkabir University of Technology (AUT), Tehran, Iran and Tehran University, Tehran, Iran, respectively, graduating all with First Class Honors. As a Ph.D. student, he has received scholarship from DAAD (German Academic Exchange Service) from 1993 to 1996 and he was with High Voltage Institute of RWTH Aachen, Aachen, Germany.

He has been holding the Assistant Professor position at AUT from 1997 to 2003, the position of Associate Professor from 2004 to 2007 and has been Professor since 2007. The power engineering group of AUT has been selected as a Center of Excellence on Power Systems in Iran since 2001. He is a member of this center. He is the author of more than 450 journal and conference papers. His teaching and research interest include power system and transformers transients and power electronics applications in power systems.

Prof. Gharehpetian was selected by the ministry of higher education as the distinguished professor of Iran and by IAEEE (Iranian Association of Electrical and Electronics Engineers) as the distinguished researcher of Iran and was awarded the National Prize in 2008 and 2010, respectively. He is a senior and distinguished member of IEEE and IAEEE, respectively, and a member of the central board of IAEEE. Since 2004, he is the Editor-in-Chief of the Journal of IAEEE.

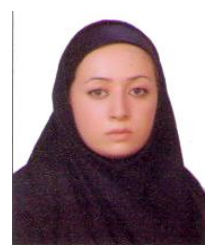

Maedeh Gholamghasemi was born in Chalous, IRAN, in 1990. She is currently B.Sc student on power engineering at Noshirvani University, Babol, Iran. Her research interests include transient analysis of power system, transformers transients analyzing and signal processing 